DOI: $10.12731 / 2306-1561-2013-4-26$

\title{
PRINCIPLES OF MODELING DEALER NETWORK
}

\author{
Lazarenko A.V., Nikolaev A.B., Solntsev A.A.
}

\section{Abstract}

The article analyzes the development strategies of dealer networks in the automotive industry. For example, automakers are creating their own dealer firms for the purpose of direct contact with customers and assigning margin, which is becoming smaller due to competition and to share it with dealers and more difficult. Add to that the authorization policy automakers service businesses without motor vehicles, as well as the policy of softfranchise, it is possible to conclude that the auto companies are moving in the direction of the capture of key positions in retail new vehicle, leaving the individual dealers selling to individual's new and used vehicles, parts and service.

Keywords: dealer network, simulation, strategy development, trade policy, warehouse.

\section{УДК 33}

\section{ПРИНЦИПЫ МОДЕЛИРОВАНИЯ ДИЛЕРСКИХ СЕТЕЙ}

\section{Лазаренко А.В., Николаев А.Б., Солнцев А.А.}

\section{Аннотация}

В статье проведен анализ стратегий развития дилерских сетей в автомобильной промышленности. Так, автопроизводители создают собственные дилерские фирмы с ичелью прямых контактов с потребителями и присвоения маржи, которая становится все меньше из-за конкуренции и делить ее с дилерами все труднее. Если добавить к этому политику авторизации автопроизводителями сервисных предприятий без торговли автомобилями, а также политику soft-franchise, то можно сделать вывод: автокомпании движутся в направлении захвата ключевых позиций в ритейле новых автомобилей, оставляя дилерам единичные продажи физическим лицам новых и подержанных автомобилей, запчастей и сервис.

Ключевые слова: дилерская сеть, моделирование, стратегия развития, торговая политика, склад.

\section{Анализ проблемы}

Автопроизводители, осваивая новый рынок, создают дилерские сети следующими способами:

- переманивание чужих дилеров, начиная с мультибрендинга; 
- привлечение для авторизованного сервиса ремонтных фирм, имеющих соответствующий опыт и материальную базу, с предоставлением им через год права торговли автомобилями;

- создание собственных или совместных предприятий для освоения рынка, затем продажа этих фирм местным предпринимателям.

Конкуренция среди автопроизводителей обострилась настолько, что авторынок стал для них неуправляемым. Автокомпании осознали потребность в разнообразии бизнес-моделей своих сетей. Большая часть авторизованных ремонтников в Европе теперь - автономные техцентры без торговли автомобилями. Автокомпаниями вводится также новый формат сетей с более мягкими стандартами, чтобы не терять независимый афтермаркет, чтобы извлекать прибыль из своей имеющейся инфраструктуры (логистические системы поставок запчастей, системы обучения, системы технической информации) в режиме, который называют “сети с мягкими франшизами" (по сравнению с более жесткими стандартами для авторизованных предприятий, облеченных правами полномочного дилера или авторизованного ремонтника). Эти бизнес-модели напоминают сети независимых ремонтников и кажутся привлекательной альтернативой для использования того сектора рынка ремонта, который является более цено-чувствительным и менее бренд-чувствительным.

\section{Анализ принципов формирования и моделирования дилерских сетей}

В работе выполнена классификация посреднических фирм (рисунок 1). Основными критериями, позволяющими классифицировать посреднические фирмы, являются уровень экономического обособления от производителей продукции и фактор перехода прав собственности на товар в процессе его перемещения по каналу товародвижения.

Такой вид посредничества как дилерство, наиболее подходит к высокотехнологической продукции, требующей регулярного сервиса. Это можно отнести к рынку машиностроения (легковые и грузовые автомобили, сельскохозяйственная техника, техника, специализированная на выполнении вспомогательных функций на предприятиях, в магазинах и т.п.) до 1991 года в бывшем СССР такая техника и запасные части к ней не продавалась, а распределялись, что было причиной постоянных проблем и простоев.

Приведены основные функции дистрибьютора, брокера и других участников дилерской сети. Дилер понимается как юридическое и физическое лицо, работающее как независимый посредник и приобретающий товар в собственность за свой счёт (в отличие от агента и комиссионера).

Анализ сложившейся структуры организации дилерских сетей показывает, что можно выделить несколько основных стратегий их развития:

- классическая дилерская сеть;

- дистрибьюторская дилерская сеть;

- ограниченная дилерская сеть. 


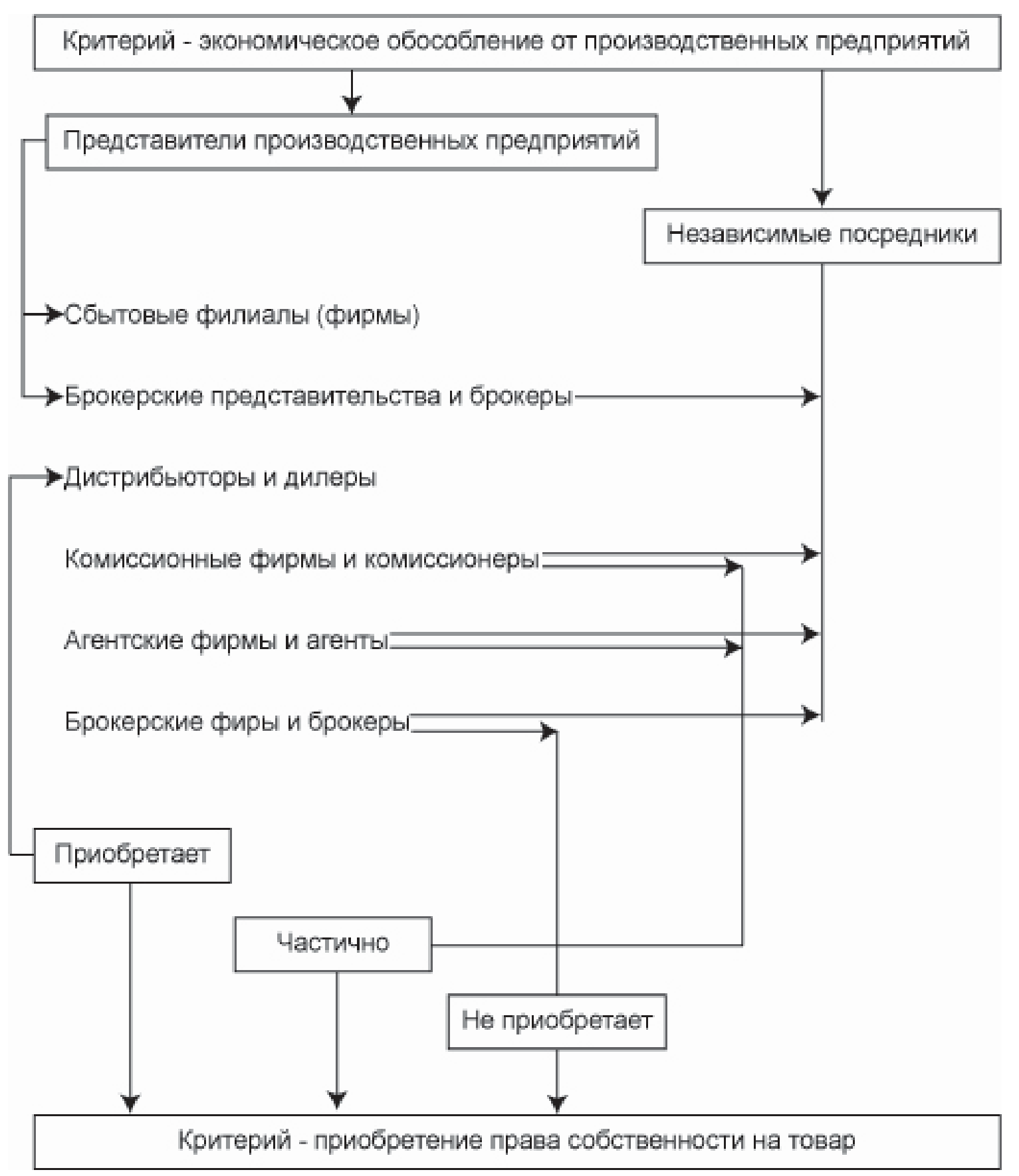

Рисунок 1 - Классификация посреднических фирм

Уровень контактов между дилерами внутри сети незначительный, и в основном базируется на основе личных взаимоотношений между менеджментом дилерских компаний. Совершенно незначителен уровень обмена информацией о клиентской базе, эффективных решений в области сервиса. Представительство зачастую контролирует ограниченное количество критериев, на основе которых ведётся работа с дилером. К таким критериям можно отнести:

- уровень продаж относительно согласованных производителем и дилером планов, зафиксированных в Дилерском соглашении, как в количественном, так и в денежном выражении; 
- отсутствие просроченной задолженности перед производителем;

- соответствие сервисных станций дилера требованиям по минимальному запасу запасных частей, квалификации механиков, площади ремонтных мастерских;

- соответствие требованиям по организации гарантийного ремонта;

- отсутствие конфликтов из-за борьбы за клиентов из других регионов.

В принципе подобная стратегия в организации дилерской сети в регионе позволяет построить эффективную дилерскую сеть, состоящую из независимых компаний. Эти компании, взяв на себя обязательства по поддержанию определенного уровня продаж, получают возможность эксклюзивно представлять на определённой территории торговую марку производителя и доступ к финансовым (товарный кредит) ресурсам производителя, а также информацию о специфике сервиса его оборудования.

Функциональные стратегии, хотя и имеют более узкую сферу деятельности, чем более высокие уровни иерархии, добавляют очень важные детали к общему плану бизнеса. Они позволяют установить те действия, подходы и практические методы, которые будут использоваться при управлении конкретной функцией, подразделением, службой.

Так, большинство стратегий можно сгруппировать, взяв за основу одну из видовых стратегий: контроль над затратами; стратегию дифференциации; фокусирование.

Стратегия контроля над затратами базируется на снижении производственных издержек по сравнению с затратами конкурентов путем обязательного контроля над затратами и/или путем регулирования размера предприятия и объема продукции, благодаря чему достигается более высокая эффективность производства. Именно низкие цены могут служить своего рода барьером для появления новых конкурентов. Для развития дилерских сетей данная стратегия связана с чётким регулированием критериев отбора дилеров для определённых регионов, в особенности в случае наличия собственной сбытовой системы.

Согласно нормативам внутренней рентабельности или иным нормативам оценки эффективности работы компании на той или иной территории, регион не был признан достаточно привлекательным для производителя.

Во многом данная стратегия является модификацией представленного выше варианта, но вместе с тем она имеет существенные отличия, которые позволяют преодолевать многие недостатки классических дилерских сетей. Вместе с тем она создаёт целый ряд проблем для производителя.

\section{Стратегия сбыта и развития дилерских сетей}

Стратегию сбыта организации в данном случае можно определить как стратегию основных подсистем организации, которая, безусловно, должна содержать в себе элементы достижения стратегических приоритетов компании и разрабатывается в рамках стратегии отдельного бизнеса или стратегии специализированных видов деятельности. 
Если же рассматривать место сбытовой стратегии в рамках иерархии формирования стратегии компании, представленной на рисунке 2 , то, безусловно, она относится к классу функциональных.

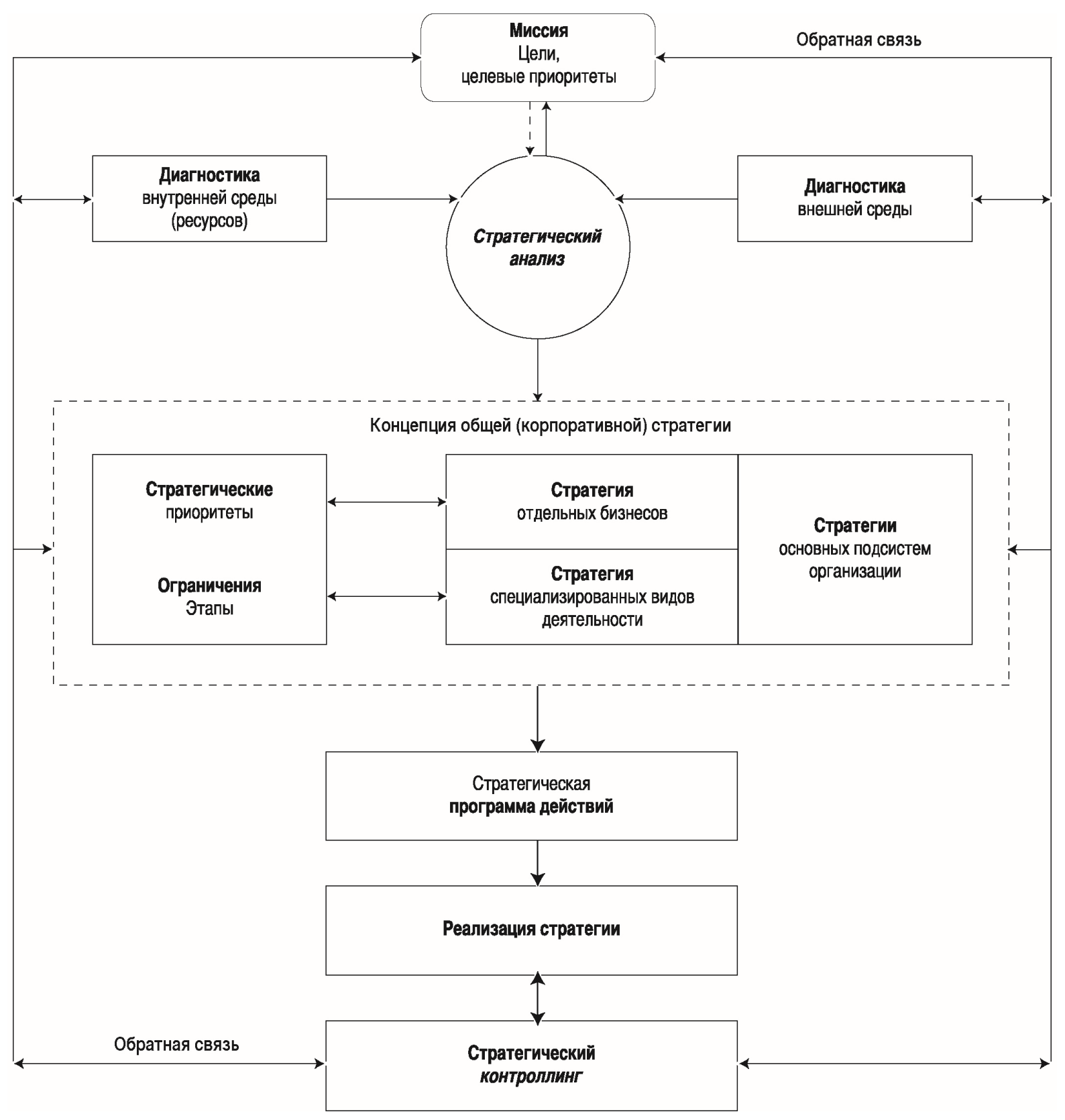

Рисунок 2 - Модель стратегического менеджмента

Стратегия дифференциации направлена на то, чтобы предоставить на рынок товары или услуги, по своим качествам более привлекательные в глазах потребителя, чем конкурирующая продукция. Эти дополнительные особые качества могут содержать следующие элементы: имидж, сервис, разветвленную сеть филиалов для оказания услуг. Стратегия дифференциации - это надежная и долгосрочная стратегия для достижения уровня прибылей выше среднего по отрасли, так как клиенты, предпочитающие одну и ту же марку, менее восприимчивы к цене. 
Дилерские сети могут служить одним из составных элементов данной стратегии, так как сеть не только дополнительное качество товара, но и система, обеспечивающая другие дополнительные качества.

\section{Формирование стратегии развития дилерской сети}

Вне зависимости от выбранной стратегии развития дилерской сети производителю после решения о необходимости открытия дилерской компании в том или ином регионе необходимо выбрать среди множества претендентов именно ту компанию, которая будет представлять его торговую марку.

Дилеры же выбирают тех поставщиков, которые гарантированно обеспечивают их качественной продукцией, пользующейся спросом; полным ассортиментом запасных частей для ремонта и обслуживания. Дилеров привлекают к сотрудничеству эффективной торговой политикой на рынке, предлагая технику, обладающую высокой конкурентоспособностью.

Большое значение имеют ёмкость рынка и его насыщенность аналогичными товарами. При малой емкости рынка и избытке конкурентных товаров возрастают трудности в подборе дилеров, усиливается борьба за них между конкурентами.

Работа по подбору дилеров и созданию сбытовой сети проводится поставщиками постоянно. Фирме-производителю и потенциальному дилеру необходимо учитывать и факторы общеэкономической среды. Всё вышесказанное можно конкретизировать и представить в виде схемы рисунок 3.

Торговая политика дилера базируется на его соглашении с поставщиком, согласно которому последний эксклюзивно поставляет в согласованный район свою продукцию и запасные части, вместе с тем, устанавливается порядок подачи заявок на запчасти и их выполнения. Дилерам предписывается содержание запаса деталей определенной номенклатуры или на определенную сумму.

Создавая дилерские склады, поставщики имеют возможность сократить запасы деталей на региональных складах, повышая тем самым оборот товаров и снижая издержки по их хранению.

\section{Заключение}

Сущность стратегии виртуальной дилерской сети заключается в отказе производителя от доминирующего положения внутри дилерской сети и уход с позиции силового влияния на работу сети, процесс отбора и контроля над работой дилеров на позиции эксперта и равноправного партнёра именно сети, а не каждого дилера в отдельности. Реализация подобной стратегии стала возможна исключительно благодаря развитию информационных технологий, которые позволяют обеспечить необходимый уровень коммуникации между всеми дилерами сети, а также самим производителем. Ключевым ресурсом в работе сети становится поток информации. 


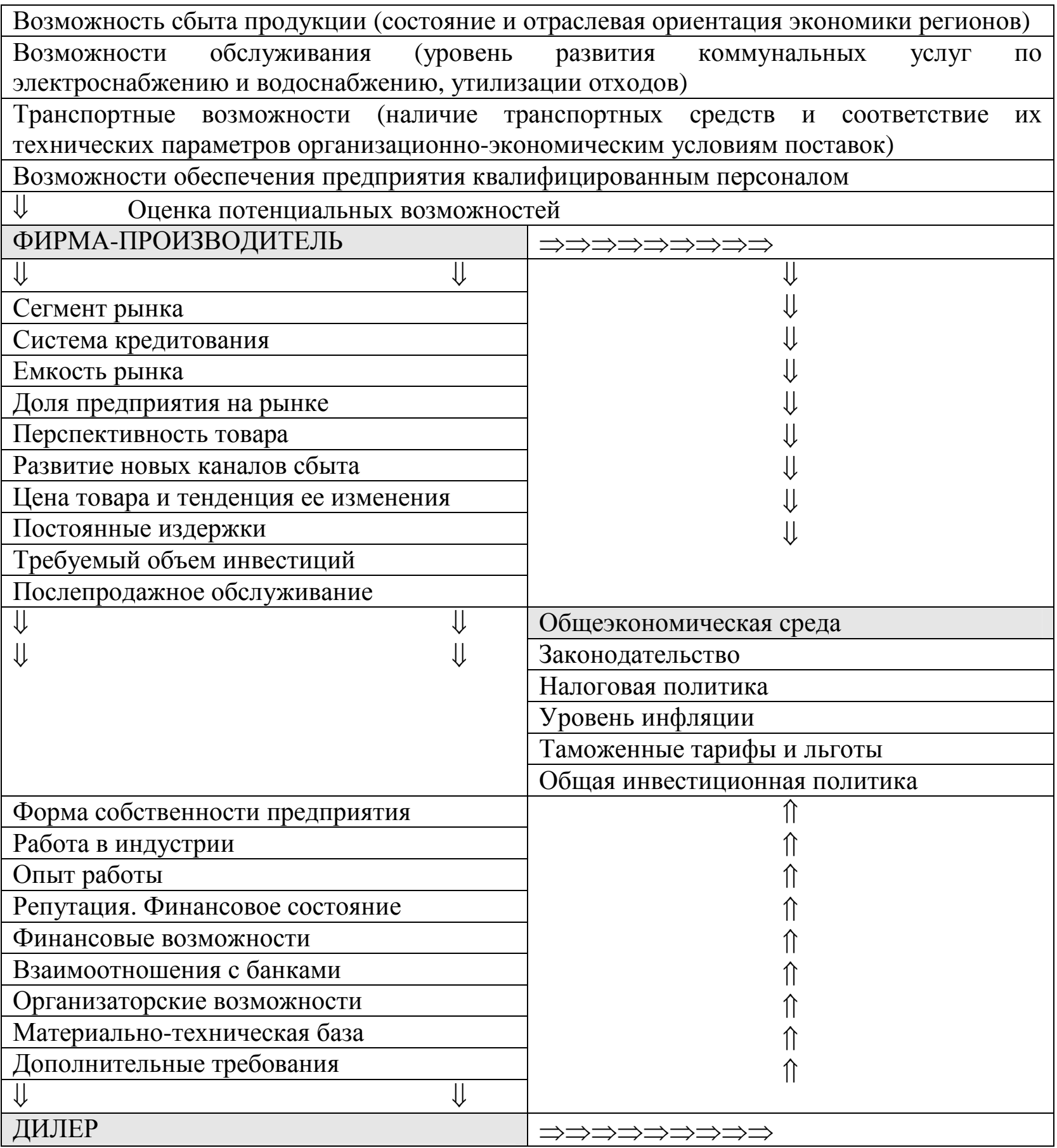

Рисунок 3 - Критерии принятия решения фирмы-производителя и дилера о сотрудничестве

\section{Список информационных источников}

[1] Агафонова М. Н. Оптовая и розничная торговля. - М.: Бератор-Пресс, 2002 стр.264.

[2] Сарычева Т.В. Организационно-экономический механизм взаимодействия партнеров в системе обеспечения автосборочных заводов комплектующими изделиями: авто-реф. дис. канд. эконом. наук. М., 2000. 
[3] Дагаев А.А. Международные стратегические альянсы в автомобильной промышленности России. // Менеджмент в России и за рубежом. - 2001. - № 2. - с. 13.

[4] Николаев А.Б., Солнцев А.А., Саная А.Г., Якунин П.С. Методы организации и моделирования дилерских сетей. // В мире научных открытий. - 2012. - №12. C163-173.

[5] Солнцев А.А., Ивахненко А.А. Формальное описание процессов движения комплектующих на основе управляемых сетей // Автоматизация и управление в технических системах. - 2013. - № 1(3); URL: auts.esrae.ru/3-69 (дата обращения: 22.11.2013).

[6] Остроух А.В., Синха Бабу Раджа Исследование информационных систем управления взаимоотношениями с поставщиками // Автоматизация и управление в технических системах. - 2013. - № 4.1; DOI: 10.12731/2306-1561-2013-4-10; URL: auts.esrae.ru/6-124 (дата обращения: 22.11.2013).

[7] Остроух А.В. Информационные технологии в научной и производственной деятельности / [ред. А.В. Остроух] - М: ООО "Техполиграфцентр", 2011. - 240 с. ISBN 978-5-94385-056-1.

[8] Куфтинова Н.Г. Процессно-ориентированный подход к автоматизации планирования и управления транспортировкой продукции предприятий промышленности / А.В. Остроух, Н.Г. Куфтинова // Вестник МАДИ - 2010. - Вып. 4(23). - C. 62-66.

[9] Остроух А.В. Исследование начального периода моделирования на точность среднеинтегральной оценки имитационных моделей / А.В. Остроух, А.А. Солнцев, Н.В. Солдатов, К.А. Новицкий, П.С. Якунин // Вестник МАДИ - 2010. Вып. 2(21). - С. 61-65.

[10] Остроух А.В. Математическая модель связей в системе диагностики электрооборудования автомобилей / А.В. Остроух, А.А. Солнцев, О.Ф. Калухов, Г.Г. Ягудаев // Вестник МАДИ - 2010. - Вып. 2(21). - С. 66-70. 